\title{
Actin cytoskeleton in the extra-ovular embryo sac of Utricularia nelumbifolia (Lentibulariaceae)
}

\author{
Bartosz Jan Plachno • Piotr Świątek
}

Received: 30 March 2011 / Accepted: 10 July 2011 /Published online: 24 July 2011

(C) The Author(s) 2011. This article is published with open access at Springerlink.com

\begin{abstract}
The actin cytoskeleton in the mature female gametophyte of angiosperms has been examined in only a few dicot and monocot species. The main purposes of this study were to identify how the actin cytoskeleton is arranged in the mature extra-ovular embryo sac in Utricularia nelumbifolia (Lentibulariaceae). We found that the extra-ovular part of the central cell has a welldeveloped actin cytoskeleton: actin microfilaments formed of long strands which run longitudinally or transversally to the long axis of the embryo sac. The exerted part of the central cell, which is exposed to the environment of the ovary chamber, is highly vacuolated and in the thin peripheral cytoplasm possesses a complicated network of actin microfilaments. The epidermal cells of the placenta that are in contact with the extra-ovular part of the embryo sac are crushed. The ultrastructure data of these cells are presented. We detected the accumulation of the actin cytoskeleton between the micropylar parts of the synergids
\end{abstract}

Handling Editor: Peter Nick

Electronic supplementary material The online version of this article (doi:10.1007/s00709-011-0306-1) contains supplementary material, which is available to authorized users.

B. J. Płachno $(\bowtie)$

Department of Plant Cytology and Embryology,

Jagiellonian University,

Grodzka 52,

31-044 Cracow, Poland

e-mail: bartosz.plachno@uj.edu.pl

P. Świątek

Department of Animal Histology and Embryology,

University of Silesia,

Bankowa 9,

40-007 Katowice, Poland and the extra-ovular part of central cell. This actin accumulation is unusual because in typical angiosperms the micropylar parts of the synergids form the apex of the female gametophyte.

Keywords Actin microfilaments $\cdot$ Female gametophyte . Embryo sac $\cdot$ Egg apparatus $\cdot$ Central cell .

Lentibulariaceae $\cdot$ Carnivorous plants

$\begin{array}{ll}\text { Abbreviations } \\ \text { ASB } & \text { Actin-stabilizing buffer } \\ \text { DAPI } & \text { 4',6-Diamidino-2-phenylindole dihydrochloride } \\ \text { ES } & \text { Embryo sac } \\ \text { AF } & \text { Actin microfilaments } \\ \text { PBS } & \text { Phosphate-buffered saline } \\ \text { SEM } & \text { Scanning electron microscope }\end{array}$

\section{Introduction}

In seed plants, there is a cross dialogue between two generations: the female gametophyte (embryo sac, ES) and maternal sporophyte (Ingram 2010; Bencivenga et al. 2011). Ovular tissues provide nutrients to the female gametophyte and also participate in the guidance of the pollen tube (Shimizu and Okada 2000; Chudzik et al. 2005; Palanivelu et al. 2003; Chae and Lord 2011). In most angiosperms, the female gametophyte remains in the ovule surrounded by sporophyte tissue; however, in a few genera, the female gametophyte grows outside the ovule, where it is partially exposed and may establish contact with other sporophyte tissue, e.g., in Philadelphus, Thesium, Galium, Utricularia, and some members of the Scrophulariaceae family (Maheshwari 1950). In Philadelphus, Thesium, 
Galium, Torenia, and some species of Lindernia not only part of the central cell is extra-ovular but also the egg apparatus itself (Krishna Iyengar 1941; Maheshwari 1950; Higashiyama et al. 2006). In these genera, the egg apparatus occupies the micropylar-apical position in the embryo sac. In the above-mentioned genera, the most famous is the genus Torenia because studies of the extraovular egg apparatus in this genus (especially Torenia fournieri) confirmed the fact that the synergids are responsible for the attraction of pollen tubes in angiosperms (Higashiyama et al. 1998, 2001, 2003). These studies also provided new data about the process of fertilization (Higashiyama et al. 1997; Yuan et al. 2002) and about the symplastic communication between the central cell and the egg apparatus (Han et al. 2000). It is worth noting the genus Utricularia in any discussion of the extra-ovular embryo sac. With some exceptions, a common characteristic in Utricularia species is that only the central cell grows outside, while the egg apparatus occurs in the part of the central cell which remains in the ovule (Płachno 2011). Therefore, this Utricularia feature is different from the model species T. fournieri in the egg apparatus position. In T. fournieri, the egg apparatus is exposed. The occurrence of the partially exposed embryo sac in Torenia also allows the actin cytoskeleton in living female gametophytes of this species to be studied (Huang et al. 1999; Yuan et al. 2002). According to Yuan et al. (2002), the actin cytoskeleton in Torenia undergoes dramatic changes that correlate with nuclear migration within the central cell and the primary endosperm. However, in Utricularia, which possesses another type of exposed embryo sac, there is a lack of data about its actin cytoskeleton. In Utricularia, the central cell forms the haustorium which interacts with placental tissue (Khan 1954; Farooq and Siddiqui 1964; Płachno and Świątek 2008). This haustorium in some Utricularia species (subgenus Utricularia, section Utricularia) is the "prelude" for producing, after fertilization, a special placentaendosperm syncytium (which possesses both maternal and paternal genetic material) (Khan 1954; Płachno and Światek 2011). This syncytium has a well-developed actin cytoskeleton (Płachno et al. 2011). Moreover, it seems that Utricularia quelchii synergids have a simpler structure compared to related Genlisea and some other angiosperms (Płachno 2011). Therefore, identifying how the actin cytoskeleton is arranged in the egg apparatus of Utricularia appeared to be worth investigating.

The main purpose of this study was to identify how the actin cytoskeleton is arranged in the mature extra-ovular embryo sac in Utricularia nelumbifolia (before pollination and fertilization). The results of fluorescent light microscopy were correlated with those of transmission and scanning electron microscopy.

\section{Material and methods}

\section{Material}

The flowers of a Brazilian species of $U$. nelumbifolia Gardner (section Iperua, Taylor 1989) were obtained from the greenhouse collection of the Botanic Garden of the Jagiellonian University in Kraków, Poland.

Immunofluorescence of cytoskeleton

For the visualization of actin microfilaments (AF), placentas with ovules were fixed in a mixture of $4 \%$ formaldehyde (freshly prepared from paraformaldehyde) and $0.25 \%$ glutaraldehyde in an actin-stabilizing buffer (ASB; $50 \mathrm{mM}$ piperazine- $N, N^{\prime}$-bis(2-ethanesulfonic acid), $10 \mathrm{mM}$ ethylene glycol-bis( $\beta$-aminoethyl ether) $N, N, N^{\prime}, N^{\prime}$ tetraacetic acid, and $1 \mathrm{mM} \mathrm{MgCl}_{2}, \mathrm{pH} 6.8$ ), overnight at $4^{\circ} \mathrm{C}$. All chemicals were obtained from Sigma (Germany) unless otherwise indicated. After fixation and three washes in an ASB, they were dehydrated in a graded ethanol series. The material was then infiltrated with Steedmans' Wax. Then $5-10-\mu \mathrm{m}$ sections were taken from the embedded ovaries and adhered to poly-Llysine-coated microscope slides. The sections were dried overnight, dewaxed in ethanol, rehydrated in an ethanolphosphate-buffered saline (PBS) series, and rinsed in PBS. After $10 \mathrm{~min}$ in methanol at $-20^{\circ} \mathrm{C}$, they were washed in PBS. Tissue sections were preincubated in 5\% bovine serum albumin in PBS for $45 \mathrm{~min}$, washed in PBS, and then incubated in a monoclonal antibody against actin (clone $\mathrm{C} 4$, ICN) overnight at $4^{\circ} \mathrm{C}$. The sections were then washed in PBS and incubated for $4 \mathrm{~h}$ in a secondary Alexa 488-conjugated anti-mouse antibody (Molecular Probes). The slides were rinsed in PBS and the nuclei were stained by 4',6-diamidino-2-phenylindole dihydrochloride (DAPI; $5 \mu \mathrm{g} / 1 \mathrm{ml}$, Sigma). The slides were then mounted in an anti-fading solution Citifluor AF1 (Agar). In the control experiments, conducted in a similar manner but omitting the first antibody, no actin staining was detected (control is presented as Supplementary material). Fluorescence was examined using Nikon Eclipse E800 and Olympus BX60 epifluorescence microscopes. More than 100 ovules were examined. The quality of fixation was checked using the differential interference contrast microscopy technique. The quality of preservation of the AF varied between the embryo sacs. The embryo sacs with collapsed cells in which serious apparent osmotic damage was observed were not included in the description of the actin cytoskeleton arrangements. However, the embryo sacs in which slight plasmolysis occurred, but the actin cytoskeleton appeared intact, were included in the study. 
Light and electron microscopy

For electron microscopy, placentas with ovules were isolated from ovaries and fixed in a mixture of $2.5 \%$ formaldehyde and $2.5 \%$ glutaraldehyde in a $0.05-\mathrm{M}$ cacodylate buffer ( $\mathrm{pH} 7.0)$ for 2 days then washed in a cacodylate buffer, postfixed in $1 \% \mathrm{OsO}_{4}$ in a cacodylate buffer for $24 \mathrm{~h}$ at $4^{\circ} \mathrm{C}$, rinsed in the same buffer, treated with $1 \%$ uranyl acetate in distilled water for $1 \mathrm{~h}$, dehydrated with acetone, and then embedded in Epoxy Embedding Medium Kit (Fluka). Semithin sections $(0.8-1,5 \mu \mathrm{m}$ thick) were cut using a Leica ultracut UCT ultramicrotome, stained with methylene blue and examined under an Olympus BX60 microscope equipped with a DP12 digital camera and AnaliSIS 3.2 (Soft Imaging System) software. Ultrathin sections $(70 \mathrm{~nm})$ were cut using a Leica ultracut UCT ultramicrotome. After contrasting with uranyl acetate and lead citrate, the sections were examined using a Hitachi H500 electron microscope. The procedure for preparing samples for Scanning electron microscope (SEM) was as described earlier (Płachno and Świątek 2009, 2010). The dried tissues were sputter-coated with gold and viewed using a HITACHI S-4700 microscope (Scanning Microscopy Laboratory of Biological and Geological Sciences, Jagiellonian University).

\section{Results}

Like the majority of angiosperm taxa, U. nelumbifolia has a so-called Polygonum-type female gametophyte. In $U$. nelumbifolia, the mature central cell can be divided into three parts: extra-ovular, central (where the secondary nucleus occurs) and the chalazal. The micropylar part of the central cell of the mature embryo sac projects out beyond the edges of the integument and grows outside the ovule (Fig. 1a, b). The embryo sac is exposed to the environment of the ovary chamber (Fig. 1a, b); however, the extra-ovular part of the central cell also penetrates the placenta tissue (Fig. 1c). This haustorial part of the central cell which penetrates the placenta has contact with a special spherical group of cells that have a thicker cell wall ("nutritive tissue") which differentiates in close proximity to the ovule base at an early stage of the development of the female gametophyte (Fig. 1c). In the micropylar part and the extra-ovular part of the central cell, AF form long strands which run longitudinally and transversally to the long axis of the embryo sac (Fig. 2a). The exposed part of the central cell, which is in contact with the environment of the ovary chamber, is highly vacuolated (Fig. 2b). A complicated network of AF is clearly visible in the thin peripheral cytoplasm of the exposed part of the central cell
Fig. 1 The morphology and anatomy of the ovule and embryo sac of $U$. nelumbifolia; a SEM micrograph of the ovule $(O v)$ and extra-ovular part of the central cell (arrow). Bar= $11 \mu \mathrm{m}$. b SEM micrograph of the extra-ovular part of the central cell (arrows), the ovule was removed for better visualization of the central cell. Bar $=200 \mu \mathrm{m}$. c A longitudinal section through the ovule, embryo sac, and part of the placenta showing the arrangement of actin in different types of cells (actin by antibody immunolabeling-green). Note the haustorial part of the embryo sac which penetrates the placenta tissue (HES) and long $\mathrm{AF}$ strands which run longitudinally to the long ES axis (small arrows); raphe $(R a)$, placenta $(P)$, integument $(I n)$, placenta epidermis $(E p)$, central cell $(C c)$, hypostase $(H)$, nutritive tissue $(N t)$, the extra-ovular part of the central cell (arrow). Bar $=10 \mu \mathrm{m}$
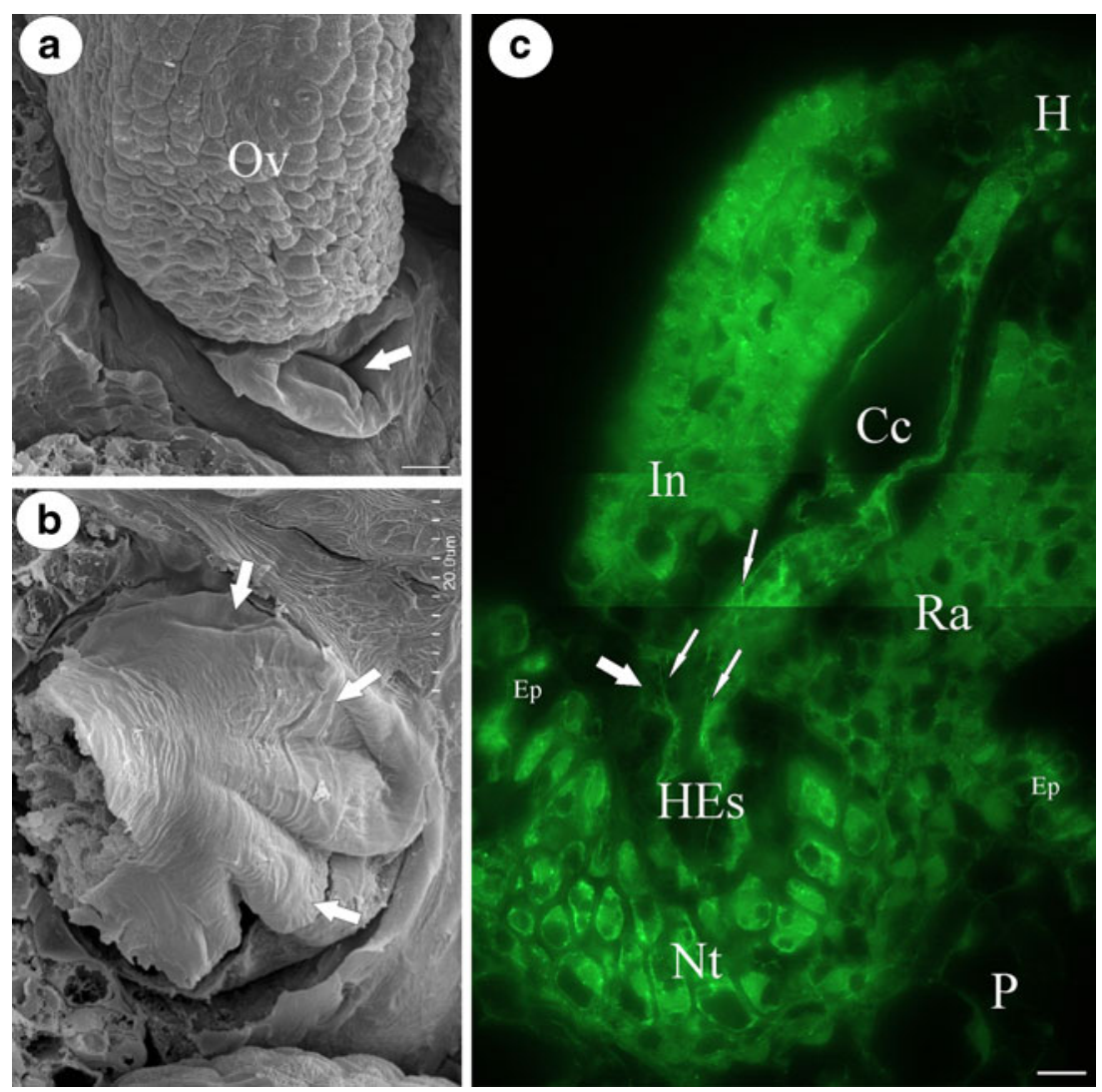
Fig. 2 The actin cytoskeleton and ultrastructure of the extraovular part of the embryo sac; a a longitudinal section showing the arrangement of actin in the central cell of the embryo sac. Note long AF strands which run longitudinally or transversally (small arrows); raphe $(R a)$, placenta $(P)$, secondary nucleus $(N)$, integument $(I n)$, central cell $(C c)$, extra-ovular part of the central cell (arrow). Bar= $22 \mu \mathrm{m}$. b A transverse section showing the complicated actin network in the extra-ovular part of the central cell $(C c)$, the arrow points to the part of the central cell that is exposed to the environment of the ovary chamber; vacuole $(V)$. Bar $=20 \mu \mathrm{m}$. c Electron micrograph showing the contact of the extra-ovular part of the central cell $(E x C c)$ with the epidermis $(E p)$ and nutritive tissue $(N T)$ of the placenta; mitochondrion $(m)$, vacuole $(V)$, starch grain $(S)$. Bar $=0.8 \mu \mathrm{m}$
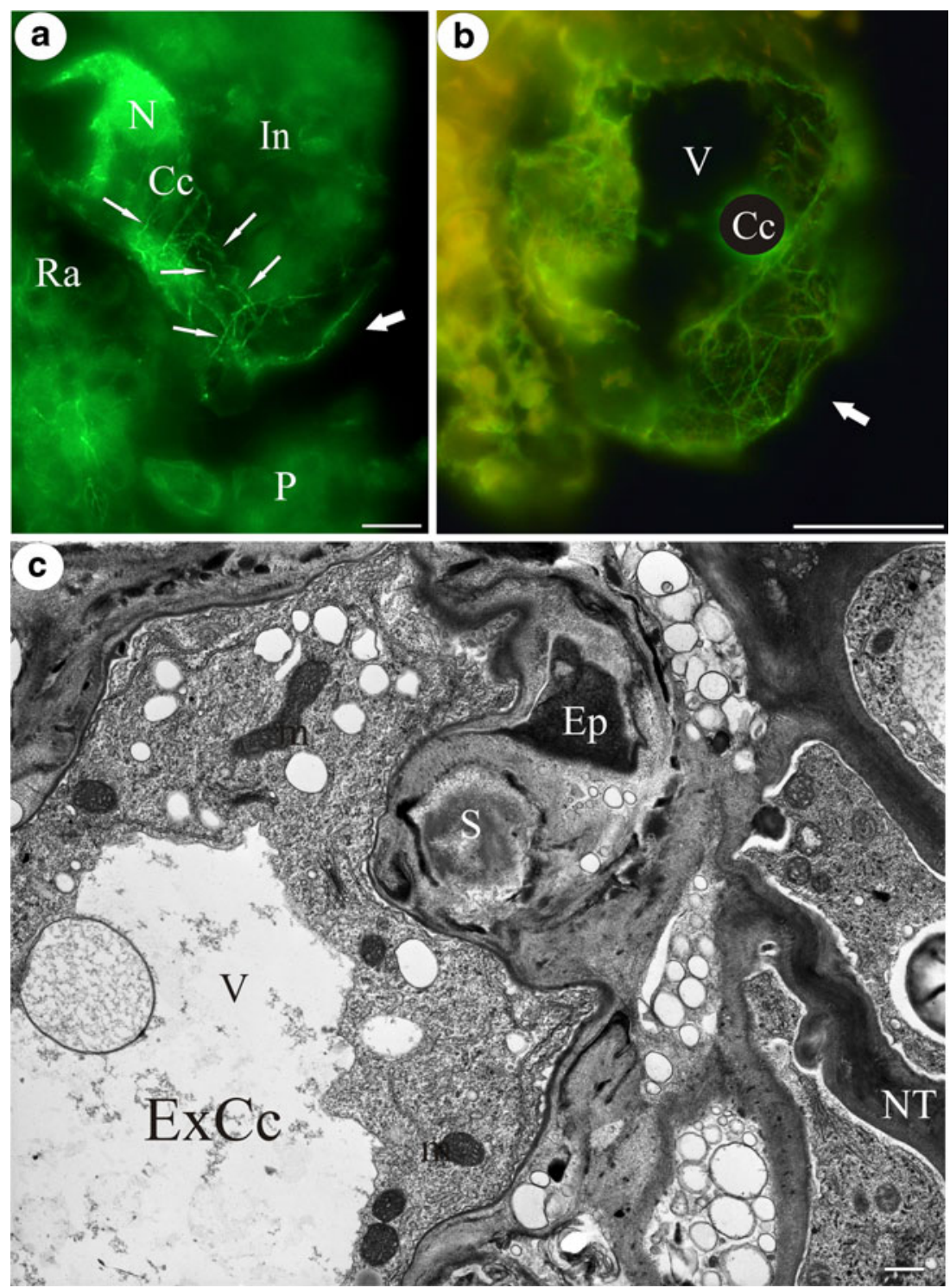

(Fig. 2b). The epidermal cells of the placenta that are in contact with the extra-ovular part of the embryo sac are crushed (Fig. 2c). In contrast to the other epidermal cells, positive signals were not observed after DAPI staining (not shown), nor were they observed in these cells after actin staining (Fig. 3a). The cell walls of these cells are partially dissolved (Fig. 2c). Thus, the extra-ovular part of the embryo sac should be considered as haustorial. In the central part of the central cell, near the secondary nucleus, bundles of microfilaments run in cytoplasmic strands (Fig. 3a) forming radial or random arrays. The chalazal part of the central cell has a cortical actin cytoskeleton in the shape of long AF arranged according to the long axis of the ES (not shown). In the synergids, AF are present throughout the cytoplasm but are concentrated at the micropylar pole (Fig. 3a) in a transverse orientation. It should be stressed that near the micropylar part of the synergids in the central cell, there are thick bundles of AF oriented longitudinally. These bundles form an actin cylinder between the synergids and the extra-ovular part of the central cell (Fig. 3b). Actin microfilaments occur around the nuclei of the synergids and also along cytoplasmic transvacuolar strands (not shown). Our observations of the actin cytoskeleton are consistent with ultrastructural data (Fig. 4a, b), e.g., a concentration of AF was detected at the micropylar synergid pole where most of the cytoplasm, nucleus, and filiform apparatuses are located (Fig. 4a). Plasmodesmata between the synergids and the central cell occur here (not shown). In addition, the part of central cell which borders the micropylar part of the synergids has cytoplasm filled with mitochondria, profiles of endoplasmic reticulum, dictyosomes, and numerous small vesicles (Fig. 4a). An egg cell is situated below the synergids (Fig. 4b). The egg nucleus and the majority of the 

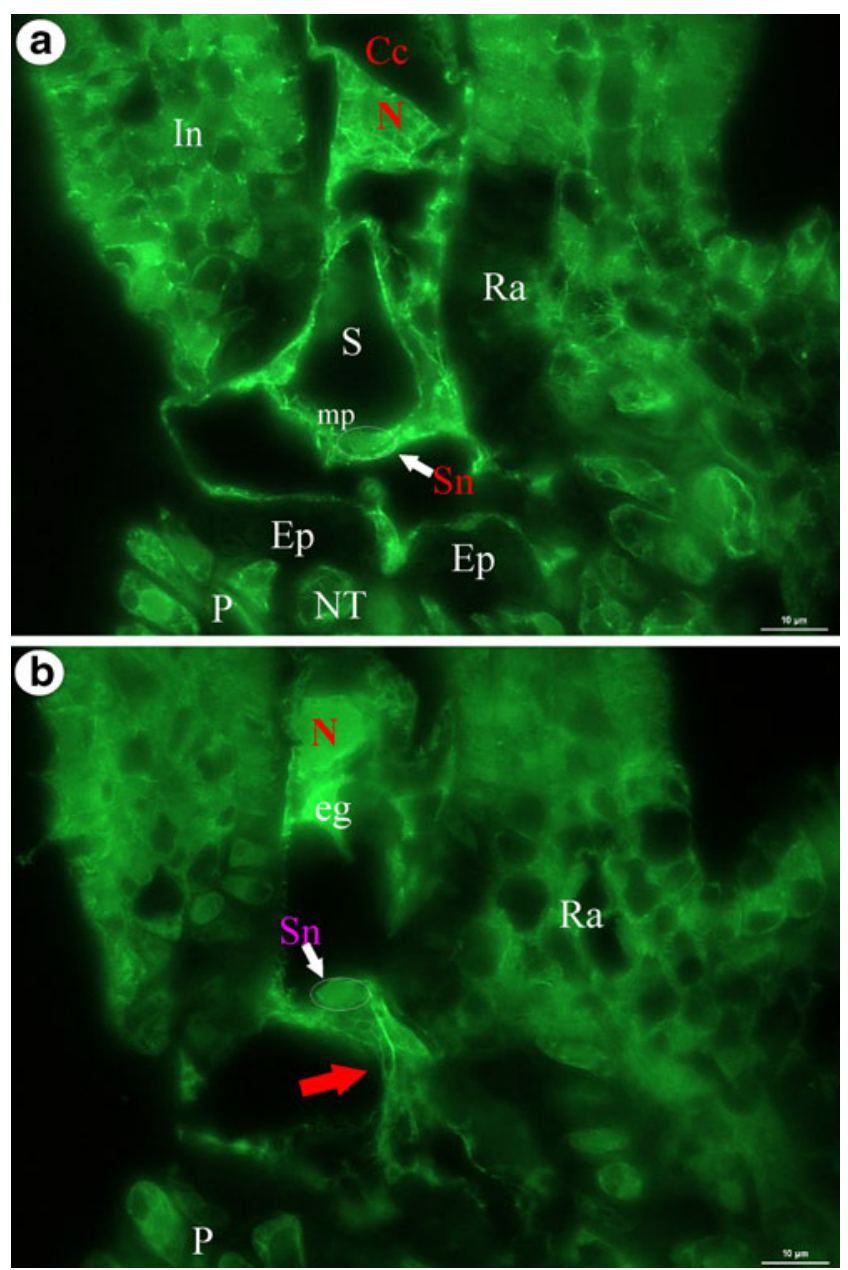

Fig. 3 Visualization of the actin cytoskeleton in the egg apparatus and the central cell; $\mathbf{a}, \mathbf{b}$ Longitudinal sections through the central and extraovular part of the embryo sac; note the AF strands in the micropylar part of the synergid $(\mathrm{mp})$ near the synergid nucleus. Also, note the strong accumulation of actin microfilaments near the micropylar part of the synergids (red arrow). No positive signal of actin was observed in the crushed placenta epidermal cells $(E p)$; synergid nucleus $(S n)$, synergid $(S)$, secondary nucleus $(N)$, egg cell $(e g)$, central cell $(C c)$, placenta $(P)$, raphe $(R a)$, integument $(I n)$, nutritive tissue $(N T)$. Bar= $10 \mu \mathrm{m}$

egg cytoplasm with mitochondria and plastids are located in the chalazal region of the cell (Fig. 4b). A few actin microfilaments were randomly oriented near the nucleus in the chalazal part of the egg cell (Fig. 4c). It should be noted that we observed only a diffuse actin network in many egg cells (Fig. 3b).

\section{Discussion}

The actin cytoskeleton in the female gametophyte of angiosperms has been examined in only a few dicot and monocot species (e.g., Webb and Gunning 1994; Huang et al. 1993, 1999; Huang and Russell 1994; Huang and Sheridan
1998; Yuan et al. 2002; Ye et al. 2002; Bednara 2003). None of these species develops such a well-developed haustorial central cell which penetrates placenta tissues, as the Utricularia species do. Thus, the enormous haustorial, extra-ovular part of the central cell, which has a complicated network of actin microfilaments, is unique to Utricularia. The question is why does Utricularia develop this extraovular part of the central cell. In the Utricularia ovule, the funiculus lacks vascular tissue, so some Utricularia species have another pathway for the transport of metabolites (mainly species from the section Utricularia, Khan 1954; Płachno and Świątek 2008, 2009) directly from the placental nutritive tissue to the embryo sac. In addition, the influence of the extra-ovular part of the central cell on the sporophytic cells of the placenta has been observed in the case of $U$. nelumbifolia (section Iperua). It appears that this highly vacuolated extra-ovular part of the central cell of $U$. nelumbifolia squashes the epidermal cells of the placenta by physical pressure. This study indicated that, in the abovementioned epidermal cells, there was protoplast disintegration and that there was also a partial dissolution of cell walls. Synergids are essential for attracting pollen tubes and for the fertilization process of angiosperms (Huang and Russell 1992; Higashiyama et al. 2001; Okuda et al. 2009), but it has only recently been found that the central cell also has its own role in attracting pollen tubes (Marton et al. 2005; Chen et al. 2007). It was proposed that signals from the micropylar part of the central cell could diffuse readily to the micropyle or that the signals produced by the central cell may be transported via the egg apparatus cells (Dresselhaus 2006; Chen et al. 2007; Liu et al. 2010). In U. nelumbifolia, the enlargement of the central cell increases the absorptive surface of the embryo sac; in addition, it may also help in signal transduction for the attraction of pollen tubes. However, further studies are necessary to determine this.

In $U$. nelumbifolia, the actin cytoskeleton of the central and chalazal parts of the central cell have an arrangement very similar to other plants where F-actin is distributed in the cortical and perinuclear region and also along the transvacuolar strands (Plumbago Huang et al. 1993; Zea, Torenia Huang et al. 1999; Arabidopsis Webb and Gunning 1994) or along the amyloplasts when the central cell is rich in starch (Arabidopsis Webb and Gunning 1994). Yuan et al. (2002), using living Torenia embryo sacs and microinjection experiments, showed that in the central cell, AF form a very dynamic system that is dependent on the phases of the development of the flower (time of anthesis) and pollination. These authors found thick bundles of AF which connected the secondary nucleus to the micropylar, cortical cytoplasm near the egg apparatus. A similar actin cylinder was found in the central cell of Galanthus nivalis (Bednara 2003). According to Yuan et al. (2002), actin in the central cell not only participates in cytoplasm streaming and 


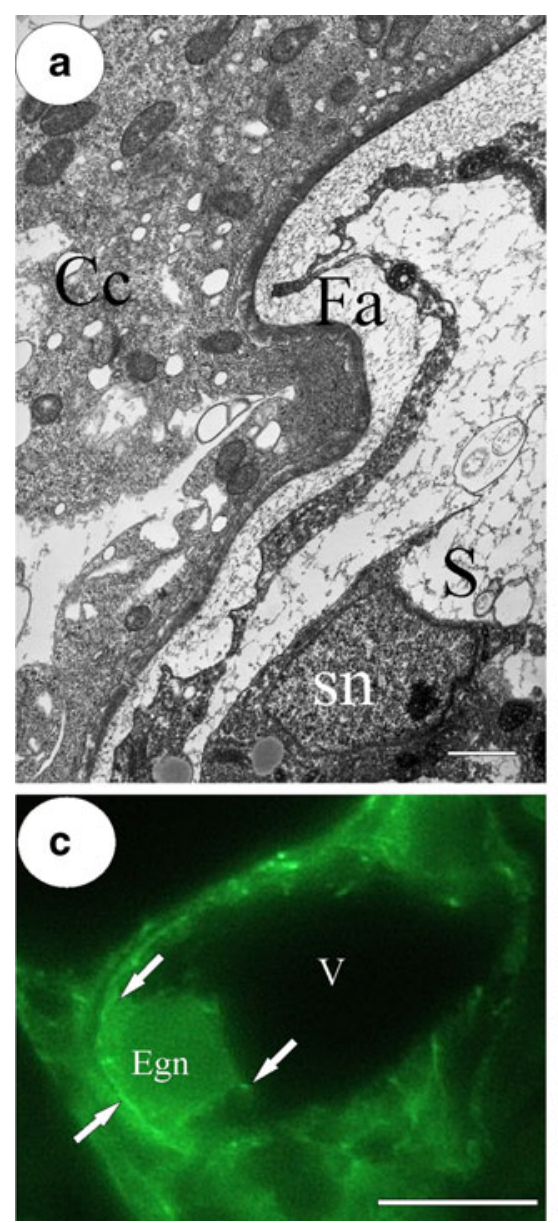

Fig. 4 Ultrastructure of the egg apparatus of U. nelumbifolia and an immunostaining of the actin microfilaments in the egg cell; a contact between the micropylar part of the synergid and the central cell; synergid $(S)$, synergid nucleus $(s n)$, central cell $(C c)$, filiform

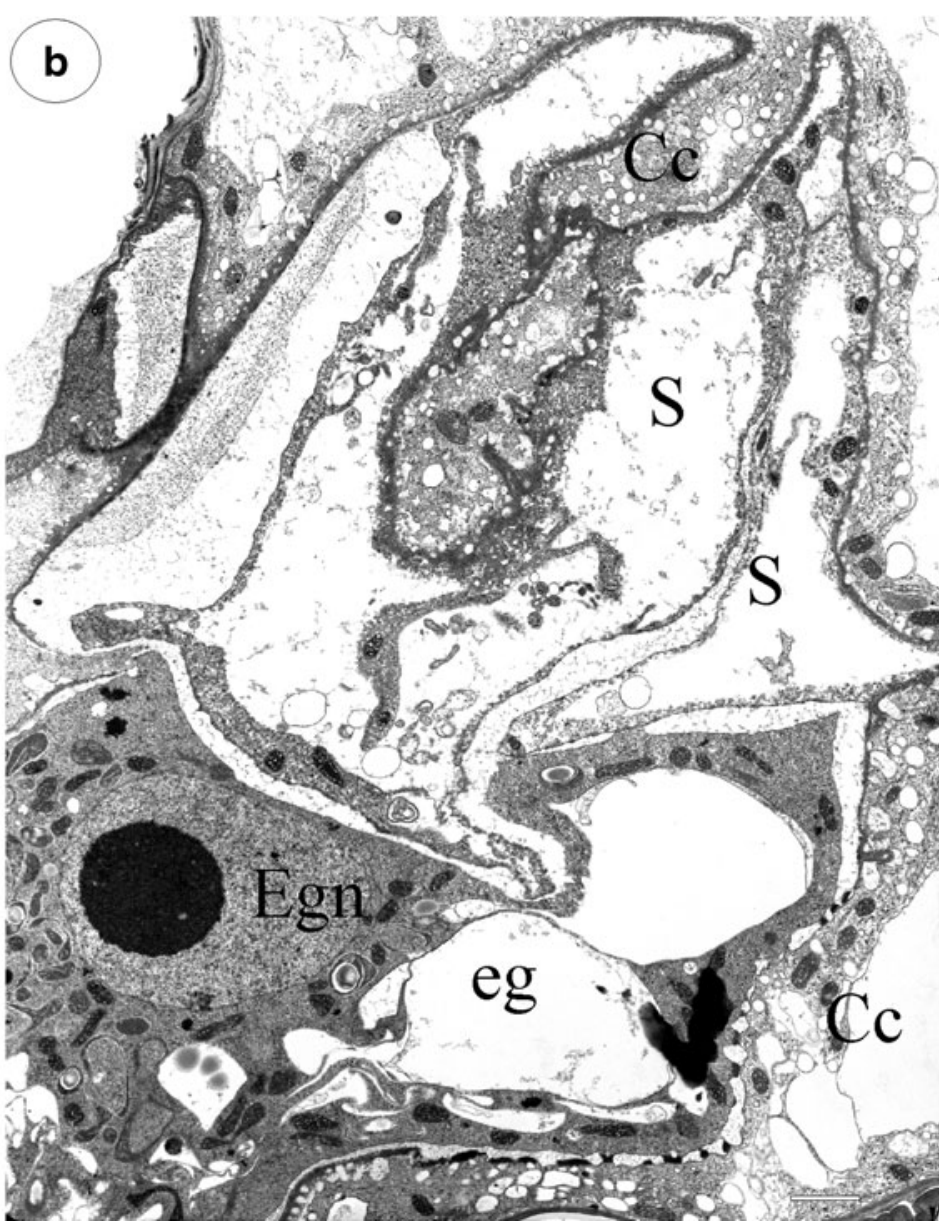

apparatus $(F a) . B a r=1 \mu \mathrm{m}$. b Ultrastructure of the egg apparatus, egg nucleus $(E g n)$, egg cell $(e g)$, central cell $(C c)$, synergid $(S)$. Bar= $1.3 \mu \mathrm{m}$. c Poor actin cytoskeleton in egg cell: actin microfilaments (arrows), egg nucleus (Egn), vacuole of the egg cell (V). Bar $=10 \mu \mathrm{m}$ organelle movements but also in the migration of the secondary nucleus to the region of the egg apparatus. As was mentioned above, in Torenia and Galanthus, the actin cylinder which connects the central cell and the egg apparatus was observed (Yuan et al. 2002; Bednara 2003). An actin cylinder-like structure was also observed in this study, however in a different location: between the micropylar parts of the synergids and the extra-ovular part of the central cell. This accumulation of actin cytoskeleton may participate in the transport of signals between the cytoplasm of the central cell and the synergids, especially since there are plasmodesmata which connect the micropylar parts of the synergids with the central cell. However, this should be experimentally proven.

Generally, in angiosperm synergids, actin microfilaments are mostly aligned longitudinally with the long cell axis (Arabidopsis Webb and Gunning 1994; Torenia Fu et al. 2000). In contrast, the actin microfilaments in $U$. nelumbifolia were aligned transversely with the long cell axis; this is probably connected with their simpler synergid structure as compared to other angiosperms (Płachno 2011) and with the orientation and structure of the filiform apparatus in this genus. In Torenia, dense actin filaments are located near the region of the filiform apparatus. Later, after the degeneration, actin forms a cap near the filiform apparatus (Fu et al. 2000). Similarly to Torenia, AF have also been detected in this region in Utricularia synergids.

The four following actin arrangements have been described for plant egg cells: (1) AF in the chalazal pole, (2) a cortical arrangement, (3) AF in cytoplasmic strands, and (4) a random arrangement (Webb and Gunning 1994; Huang et al. 1993, 1999; Huang and Russell 1994; Bednara 2003). Similar to other angiosperms, the AF concentrate at the chalazal pole of the egg cell in U. nelumbifolia. The poor AF cytoskeleton in the Utricularia egg may be connected to the inactive physiological stage (resting phase) of the egg cell of angiosperms or actin signals may simply label globular actin. 


\section{Conclusions}

This study has shown that the $U$. nelumbifolia embryo sac has some unusual characteristics in AF arrangement comparison with typical angiosperms: The extra-ovular part of the central cell has a well-developed actin cytoskeleton - actin microfilaments formed of long strands run longitudinally and transversally to the long axis of the embryo sac. The exerted part of the central cell, which is exposed to the environment of the ovary chamber, is highly vacuolated, and in the thin peripheral cytoplasm, a complicated network of actin microfilaments was present.

The accumulation of the actin cytoskeleton between the micropylar parts of the synergids and the extra-ovular part of the central cell is unusual because in typical angiosperms the micropylar parts of the synergids form the apex of the female gametophyte.

\begin{abstract}
Acknowledgments This paper is dedicated to Professor Romana Izmaiłow (Department of Plant Cytology and Embryology, Institute of Botany, Jagiellonian University) for her great contribution to research on plant embryology. This study was funded by grant N N304 002536 from the Polish Ministry of Science and Higher Education. We cordially thank the director of the Botanic Garden of the Jagiellonian University, Prof. Bogdan Zemanek, for permission to use plants from the Garden collections and also gardener, Lucyna Kurleto, who conscientiously cares for the collection of carnivorous plants in the Garden. We also especially thank both Dr. Małgorzata Kozieradzka-Kiszkurno and M.Sc. Małgorzata Ignatowska (University of Gdańsk) for their expert technical help. The comments to the manuscript of Prof. Ewa Kurczyńska are kindly acknowledged.
\end{abstract}

Conflict of interest statement The authors declare that they have no conflict of interest.

Open Access This article is distributed under the terms of the Creative Commons Attribution Noncommercial License which permits any noncommercial use, distribution, and reproduction in any medium, provided the original author(s) and source are credited.

\section{References}

Bednara J (2003) Rola szkieletu cytoplazmatycznego w rozmnażaniu roślin. (Role of cytoskeleton in plants reproduction.). Kosmos 52:469-479

Bencivenga S, Colombo L, Masiero S (2011) Cross talk between the sporophyte and the megagametophyte during ovule development. Sex Plant Reprod 24. doi:10.1007/s00497-011-0162-3

Chae K, Lord EM (2011) Pollen tube growth and guidance: roles of small, secreted proteins. Ann Bot. doi:10.1093/aob/mcr015

Chen Y-H, Li H-J, Shi D-Q, Yuan L, Liu J, Sreenivasan R, Baskar R, Grossniklaus U, Yang W-C (2007) The central cell plays a critical role in pollen tube guidance in Arabidopsis. Plant Cell 19:3563-3577

Chudzik B, Zarzyka B, Śnieżko R (2005) Immunodetection of arabinogalactan proteins in different types of plant ovules. Acta Biol Cracov Ser Bot 47:139-146

Dresselhaus T (2006) Cell-cell communication during double fertilization. Curr Opin Plant Biol 9:41-47
Farooq M, Siddiqui SA (1964) The embryology of Utricularia stellaris Linn. f. Sci Cult 30:394-395

Fu Y, Yuen M, Huang BQ, Yang HY, Zee SY, O’Brien TP (2000) Changes in actin organization in the living egg apparatus of Torenia fournieri during fertilization. Sex Plant Reprod 12:315-322

Han YH, Huang BQ, Zee SY, Yuan M (2000) Symplastic communication between the central cell and the egg apparatus cells in the embryo sac of Torenia fournieri Lind. before and during fertilization. Planta 211:158-162

Higashiyama T, Kuroiwa H, Kawano S, Kuroiwa T (1997) Kinetics of double fertilization in Torenia fournieri based on direct observations of the naked embryo sac. Planta 203:101-110

Higashiyama T, Kuroiwa H, Kawano S, Kuroiwa T (1998) Guidance in vitro of the pollen tube to the naked embryo sac of Torenia fournieri. Plant Cell 10:2019-2031

Higashiyama T, Yabe S, Sasaki N, Nishimura Y, Miyagishima S, Kuroiwa H, Kuroiwa T (2001) Pollen tube attraction by the synergid cell. Science 293:1480-1483

Higashiyama T, Kuroiwa H, Kuroiwa T (2003) Pollen tube guidance: beacons from the female gametophyte. Curr Opin Plant Biol 6:36-41

Higashiyama T, Inatsugi R, Sakamoto S, Sasaki N, Mori T, Kuroiwa H, Nakada T, Nozaki H, Kuroiwa T, Nakano A (2006) Species preferentiality of the pollen tube attractant derived from the synergid cell of Torenia fournieri. Plant Physiol 142:481-491

Huang BQ, Russell SD (1992) Female germ unit: organization, isolation, and function. Int Rev Cytol 140:233-293

Huang BQ, Russell SD (1994) Fertilization in Nicotiana tabacum: cytoskeletal modifications in the embryo sac during synergid degeneration. Planta 194:200-214

Huang BQ, Sheridan FW (1998) Actin coronas in normal and indeterminate gametophyte 1 embryo sacs of maize. Sex Plant Reprod 11:257-264

Huang BQ, Pierson ES, Russell SD, Tiezzi A, Cresti M (1993) Cytoskeletal organisation and modification during pollen tube arrival, gamete delivery and fertilisation in Plumbago zeylanica. Zygote 1:143-154

Huang BQ, Fu Y, Zee SY, Hepler PK (1999) Three-dimensional organization and dynamic changes of the actin cytoskeleton in embryo sacs of Zea mays and Torenia fournieri. Protoplasma 209:105-119

Ingram GC (2010) Family life at close quarters: communication and constraint in angiosperm seed development. Protoplasma 247:195-214

Khan R (1954) A contribution to the embryology of Utricularia flexuosa Vahl. Phytomorphol 4:80-117

Krishna Iyengar CV (1941) Development of embryo-sac and endosperm haustoria in Torenia cordifolia Roxb., and T. hirsuta Benth. Proc Nat Inst Sci India 7:61-71

Liu Y, Yan Z, Chen N, Di X, Huang J, Guo G (2010) Development and function of central cell in angiosperm female gametophyte. Genesis 48:466-478

Maheshwari P (1950) An introduction to the embryology of angiosperms. McGraw-Hill, New York

Marton ML, Cordts S, Broadhvest J, Dresselhaus T (2005) Micropylar pollen tube guidance by egg apparatus 1 of maize. Science 307:573-576

Okuda S, Tsutsui H, Shiina K, Sprunck S, Takeuchi H, Yui R, Kasahara RD, Hamamura Y, Mizukami A, Susaki D et al (2009) Defensin-like polypeptide LUREs are pollen tube attractants secreted from synergid cells. Nature 458:357-361

Palanivelu R, Brass L, Edlund AF, Preuss D (2003) Pollen tube growth and guidance is regulated by POP2, an Arabidopsis gene that controls GABA levels. Cell 114:47-59

Płachno BJ (2011) Female germ unit in Genlisea and Utricularia, with remarks about the evolution of the extra-ovular female gametophyte in members of Lentibulariaceae. Protoplasma 248:391404. doi:10.1007/s00709-010-0185-x 
Płachno BJ, Świątek P (2008) Cytoarchitecture of Utricularia nutritive tissue. Protoplasma 234:25-32

Płachno BJ, Świątek P (2009) Functional anatomy of the ovule in Genlisea with remarks on ovule evolution in Lentibulariaceae. Protoplasma 236:39-48

Płachno BJ, Świątek P (2010) Unusual embryo structure in viviparous Utricularia nelumbifolia, with remarks on embryo evolution in genus Utricularia. Protoplasma 239:69-80. doi:10.1007/s00709009-0084-1

Płachno BJ, Świątek P (2011) Syncytia in plants: cell fusion in endospermplacental syncytium formation in Utricularia (Lentibulariaceae). Protoplasma 248:425-435. doi:10.1007/s00709-010-0173-1

Płachno BJ, Świątek P, Kozieradzka-Kiszkurno M (2011) The F-actin cytoskeleton in syncytia from non-clonal progenitor cells. Protoplasma 248:623-629. doi:10.1007/s00709-010-0209-6
Shimizu KK, Okada K (2000) Attractive and repulsive interactions between female and male gametophytes in Arabidopsis pollen tube guidance. Development 127:4511-4518

Taylor P (1989) The genus Utricularia - a taxonomic monograph. Kew B 14:1-735

Webb MC, Gunning BES (1994) Embryo sac development in Arabidopsis thaliana. II. The cytoskeleton during megasporogenesis. Sex Plant Reprod 7:153-163

Ye XL, Yeung EC, Zee SY (2002) Sperm movement during double fertilization of a flowering plant, Phaius tankervilliae. Planta 215:60-66

Yuan Ming Fu, Ying WF, Bing-Quan H, Zee S-Y, Hepler PK (2002) Fertilization in Torenia fournieri: actin organization and nuclear behavior in the central cell and primary endosperm. Science in China 45:211-22412 